\title{
On Actualization of Images A comparative study between two translations of A Psalm of Life
}

\author{
Jun $Y \mathrm{e}^{1, \mathrm{a}}$ \\ ${ }^{1}$ School of Foreign Languages, Wuhan University of Technology, Wuhan, P.R.China, \\ aE-mail: yejun725@163.com
}

Keywords: A Psalm of Life, literary translation, Image-G, aesthetics.

\begin{abstract}
A Psalm of Life written by Henry Wadsworth Longfellow is the first English poem translated into Chinese and there have been lots of versions of it. This assay aims at applying the image-G reproduction theory promoted by Jiang Qiuxia in translation criticism by analyzing two translations of this poem. It is found that the reproduction of images plays an important role in literary translation and weather the image-G can be actualized well greatly influences the aesthetic effect of the translation.
\end{abstract}

\section{Introduction}

According to Peter Newmark, linguistic functions have been put into six categories: informative function, expressive function, vocative function, aesthetic function, phatic function and metalingual function. Poems possess the beauty in form, sound and meaning. So as for the translation of poetic works, it is important to realize the expressive function and the aesthetic function in the target language. In order to reproduce the original beauty, a translator ought to retain the original meaning and artistic conception. What is most important for him to do in translating a poetic work is to keep its original conception.

One of the prominent features of poetic language is that lots of images are used. Those images form the aesthetic conceptions, which are the soul of the poem. So how to reproduce those images becomes the essential problem of the translation of poetic works.

A Psalm of Life is the first English poem translated into Chinese, so there have been all kinds of versions. This essay tries to use an aesthetic approach to discuss the Huang Gaoxin's version and Huang Xinqu 's version. According to the image-gestalt promoted by Jiang Qiuxia, literary translation should focuses on the "image-gestalt" and its actualization, both mental and linguistic actualization. We may also find that this theory can be put into translation criticism.

\section{Gestalt images}

\subsection{Images in the general sense}

Conventionally, image is the constitution of an existing object which the reader or hearer or perceiver mentally creates through his given knowledge, or the formulation of a non-existing for defamiliar object under his psychological operation of perception and imagination. Here images are not the narrow sense of a metaphor, a symbol, nor in that of whatever figure of speech. It is most comprehensive in that it means any piece of descriptive writing that can evoke mental pictures through visual imagination. There are visual image, auditory image, olfactory image, tactile image, gustatory image, kinaesthetic and abstract image. So image may appeal to the eyes, the ears, the nose, or even to the taste. A poetic text is usually composed of a series of images_concrete and allusive, mimetic and inventive. 


\subsection{Image in the gestalt sense}

The image-G refers to the representation (mental and verbal) of a certain scene, a certain character or an event as a whole in a literary text. When referred to as a gestalt, the image is mainly stressed for its overall qualities. To apply the gestalt category to image analysis is to study or understand images as functional wholes, to discover the position of parts in the wholes, their degree of relative independence, and the articulation of larger wholes into subwholes. An image-G can be constituted by a single word, a sentence, a paragraph, or even a text. Image-G in this study mainly refers to macro images of a scene, a character, hence usually the constitution of a paragraph or a whole text (e.g. a poem). The gestalt image in literary work of art is found to possess two features: it establishes a pattern within a textual organization, focusing the meaning of a textual organization as a whole; it creates gestalt qualities such as atmosphere, tone.

\subsection{Image-G and the aesthetic effect of harmony}

The image-G model in literary translation is found to perform two major functions: it focuses a certain textual organization and its meaning as a whole; it creates aesthetic qualities such as mood, atmosphere in a gestalt sense. The meaning in any organization is greatly influenced by the meaning of the whole organization. So during the translating, the text must be treated as a functional and meaningful integrated whole. To make a translated text meaningful, not only must the relevant elements be represented, but they must also be properly integrated. On the other hand, to actualize or formulate images in literary translation can help the translator to experience, formulate and then reproduce a scene with similar mood, tone, sensation, etc. Image-G is a thematic configuration which is linguistically cohesive, thematically coherent and aesthetically affective and consistent. This conception in literary translation is different from the idea of deep structure in that the latter emphasizes the transference of a semantic meaning while the former focused on an aesthetic gestalt as well as an overall semantic meaning. In literary translation, instead of replacing one linguistic item for another, the translator is to formulate a gestalt image and realize a target text based on this image.

\section{Comparative study}

\subsection{Introduction of the poet and the poem}

The poet, Henry Wadsworth Longfellow(1807-1882), was the best loved of American poets over the world. Longfellow wrote on obvious themes which appeal to all kinds of people. His poems are easily understood; they sing their way into the consciousness of those who read them. Above all, there is joyousness in them, a spirit of optimism and faith in the goodness of life which evokes immediate response in the emotions of his readers.

Mr. Longfellow said of this poem: "I kept it some time in manuscript, unwilling to show it to any one, it being a voice from my inmost heart, at a time when I was rallying from depression." Before it was published in the Knickerbocker Magazine, October, 1838, it was read by the poet to his college class at the close of a lecture on Goethe. Its title, though used now exclusively for this poem, was originally, in the poet's mind, a generic one. He notes from time to time that he has written a psalm, a psalm of death, or another psalm of life. The 'psalmist' is thus the poet himself.

This poem is the first English poem translated into Chinese and there have been lots of versions of it. It was first published in 1839, which is a period of the developing capitalism in America. This poem is enthusiastic and optimistic. It affirms the passion for the beautiful life and denies the pessimistic attitude toward life. This poem has revealed the features of that era and evokes immediate response in the emotions of the readers. so it is marked as "real heart-throb of America". 
There are thirty-nine sentences in this poem and four sentences in each stanza. The first two stanzas aim at the decadent attitude that "Life is but an empty dream" and directly expresses that "Life is real! Life is earnest!" In the following four stanzas the poet further points out that since life is not a dream, we should "Act - act in the living Present". The seventh and the eighth stanzas set the examples of outstanding people to stimulate the readers to leave the "Footprint on the sands of time". The last stanza appeal everyone to "be up and doing".

The two versions translated by Hung Gaoxin and Huang Xinqu. Both of the two versions have reproduced the images in the original poem. But specifically speaking, different translations have achieved the aesthetic effect in different degree. In the following part, the differences will be discussed.

\subsection{Comparative study between the two versions}

\section{Example 1}

Tell me not in mournful numbers,

Life is but an empty dream!

These are the first two lines of this poem. The poet wants to argue against the pessimistic attitude toward life so it put this view at the very beginning of the poem. From the two lines, readers are likely to hear the voice "in a mournful numbers". "Numbers" usually means "symbol or word indicating a quantity of unites; numeral ". But in this text, it may mean "song, dance, etc, esp. in a theatrical performance" ". That's why in Xin's version this word is translated into "chang". Is it suitable here? Let's look at the translation of two lines as a whole and imagine: If a person holds a pessimistic attitude toward life, does he have the mood to sing? We usually sing to express our good feeling, maybe praise somebody or extol something. Generally speaking, we sing when we are in a optimistic mood, at least in a good mood. Can we sing that "Life is but an empty dream?" If we really think so, we may murmur these words out but not sing. The poet intends to show a decadent picture in these two lines. But in Xin's translation, the character "chang" seems to be so antipathetic. The gestalt-G emphasizes the effect of harmony and also the achievement of harmonious effect in the target text, while this character breaks this effect in the translation. In Qu's version, this meaning is rendered into "di yin", which is much more suitable than "chang". "yin" has many meanings: "(1)sing (2)groan" Just this one character not only includes the original meaning, but also reproduce the whole image in the source text in a vivid way. "di yin" here means crooning. People croon when they are painful, when they are suffering and in agony. So this character meets the need of reproducing the original image. From the translation, we are likely to hear a voice murmuring that life is hopeless and desperate and the image of the people who live a dreaming and befuddled life appear vividly on the paper. In the translation, auditory image is reproduced successfully in Qu's version.

Example 2

Not enjoyment, and not sorrow, Is our destined end or way;

but to act, that each to-morrow. Finds us father than to-day.

This stanza denies that life is neither enjoyment nor sorrow but to seize the time and opportunity and act. Xin's version and Qu's version of the two lines are quite similar to each other. Both of the translations express the original meaning of the source text. But the two translator deal with the next two lines in different ways. After denies the pessimistic attitude that life is enjoyment and sorrow, the following part should answer the question: "What is life on earth?" Because having read the poem here, it is natural for the reader to arouse the question. In Qu's version, this question is clearly answered. Let's look at the structure of the source text: "Not... and not... but...": it first negates the decadent point and then sets up its own point. This structure makes the point more impressive and also more deep-set. This structure has set up the harmony of the meaning and the form. And in Qu's

\footnotetext{
${ }^{1}$ Oxford Advanced Learner's English-Chinese Dictionary, Fourth Edition, The Commercial Press and Oxford University Press. 1999.

2 同 1
} 
translation, "neither. . . nor. . . but. . ." achieve the effect of harmony. While in Xin's version, it uses "neither. . . nor. .." structure to denies the desperate point. Having read here, the readers expect to get the poet's point directly. But "xing dong ba" appears suddenly, which seems too abrupt to the readers. Literary translation or reproduction is an instaurative action, which does not just mean the inclusion of necessary elements, but is to build the text into a logical and aesthetic consistency. By consistency it means the coherent organization of a linguistic text always keeping to a certain course, a certain gestalt quality. So the latter version breaks the aesthetic effect that it has in the original text and fails to meet the need of reproducing it in the target text.

In the sentence "that each to-morrow Finds us father than to-day", the verb "find" is very typical use of English. "Find" means "come across, discover somebody or something"." But sometimes the subject is a lifeless thing which cannot really "find" something. And there are also some other verbs used like this. Take this sentence for example: "In the last decade the world witnessed China's accelerated economic reform and advancement onto the world stage. " In English language, this use is acceptable. But when translated into Chinese, it should be adjusted. In Xin's version, the word "find" was rendered into "fa xian(discover)" directly. It makes the translation looks very strange because in Chinese we seldom use "ming tian(tomorrow)" as the subject of the verb "discover". In literary work of art, the image-G is engendered by a harmonic schema - a particular organization of elements which grants certain privileges to some aspects and thus established accents in the composition. Just as the dominant for the principal tonalities in a musical work, and the principal tones which are established in a painting, the accentuating role in literature is fulfilled by certain wording or rhetoric arrangement that constitutes the accent. In literary translation, it is through the agency of harmony that the translator is able to grasp the whole image, and reversely, in translational production, it is by means of the gestalt image mentally actualized that he is able to create a text with an aesthetic effect of harmony. But in Xin's version just a single verb has broken the aesthetic harmony. In Qu's version, the verb is rendered into "shi(make)" which agrees with the subject "tomorrow" so as to keep the beauty of images in the poem.

\section{Conclusion}

In this comparative study between the two translations of A Psalm of Life, three examples have been analyzed. This analysis is not to decide which translation is better than the other, but to conclude that the proper reproduction of the images is essential in a good translation. To actualize or formulate images in literary translation can help the translator to experience, formulate and then reproduce a scene with similar mood, tone, sensation. In literary translation, instead of replacing one linguistic item for another, the translator is to formulate a gestalt image and realize a target text based on this image. If the translator does it well, he can translate well, and vice versa.

\section{References}

[1] Yu Yungen, A Series of Translation Studies in China [C] , Hubei Education Press.pp 75-76, 2000

[2] Jiang Qiuxia, Aesthetic process in Literary Translation [D], The Commercial Press, pp86-90,2002

[3] Liu Chongde, Ten Lectures on Literature Translation [C] , China Translation Corporation.pp 21-24,2003

[4] Qin Xiubai, Essentials of English Stylistics [M] ,Shanghai Foreign Language Education Press. Pp154-155,2002

\footnotetext{
${ }^{3}$ Oxford Advanced Learner's English-Chinese Dictionary, Fourth Edition, The Commercial Press and Oxford University Press. 1999.
} 